\title{
Análise crítico-comparativa das regulamentações brasileira, estadunidense e britânica de qualidade microbiológica de biossólidos para uso agrícola
}

\author{
Critical and comparative analysis of the Brazilian, American and British \\ regulations on microbiological quality of biosolids for agricultural use
}

\section{Rafael K. X. Bastos | Paula Dias Bevilacqua | David Duncan Mara}

Data de entrada : 22/05/2012 | Data de aprovação: 03/09/2012

Resumo

Apresenta-se uma leitura crítica-comparativa das regulamentações do Brasil, dos Estados Unidos da América (EUA) e Reino Unido sobre uso agrícola de biossólidos. Destacam-se convergências e divergências entre essas três peças normativas e, sob a perspectiva de avaliação de risco à saúde, discutem-se as exigências de qualidade microbiológica dos biossólidos e as restrições de uso impostas nas respectivas normas.

Palavras-chave: biossólidos, organismos indicadores, patógenos, saúde, risco de infecção.

\section{Abstract}

A critical and comparative evaluation of the regulations for biosolids use in agriculture in Brazil, in the USA and in the UK is presented. Similarities and divergences between these regulations are highlighted, and their requirements for biosolids microbial quality and use restrictions are discussed in the context of health risk assessment.

Key-words: biosolids, health, indicator organisms, pathogens, risk of infection.

Rafael K. X. Bastos*

Engenheiro Civil. Doutor em Engenharia Sanitária. Professor do Departamento de Engenharia Civil, Universidade Federal de Viçosa

Paula Dias Bevilacqua

Médica Veterinária. Doutora em Epidemiologia Professora do Departamento de Veterinária, Universidade Federal de Viçosa.

David Duncan Mara

Engenheiro Civil. Doutor em Engenharia Sanitária. Professor do Departamento de Engenharia Civil, Universidade de Leeds, UK.

*Endereço para correspondência: Universidade Federal de Viçosa. Departamento de Engenharia Civil. Viçosa-MG. 36570-000.

Telefone: 313899 2356. Fax: 313899 1481.Email: rkxb@ufv.br 


\section{Introdução}

A produção de lodo de esgotos vem aumentando em todo o mundo como resultado do crescimento populacional e das exigências cada vez mais restritivas de tratamento de efluentes. Nos EUA, estima-se que em 2004 tenham sido produzidas aproximadamente 7,2 milhões de toneladas de lodo de esgotos ${ }^{1}$ (LeBLANC et al., 2008). Na Europa, a produção de lodo em 2005 era estimada em 8-10 milhões de toneladas (IRANPOUR et al., 2004). Em alguns países, incluindo o Brasil, o manejo do lodo de esgotos talvez não seja ainda alvo de grande preocupação, mas eventualmente, ou inevitavelmente, será, pois a atual cobertura limitada dos serviços de tratamento de esgotos é um desafio a ser superado. Em um dos poucos estudos sobre produção de lodo de esgotos no país, Machado et al. (2004), com base em banco de dados de 275 estações de tratamento (ETEs) tratando esgotos de aproximadamente $12,8 \mathrm{mi}-$ lhões de habitantes, estimaram que 151.700 toneladas de lodo são produzidas por ano, o que corresponde à média per capita de 33 gramas por dia.

Em paralelo ao crescimento da produção de lodo de esgotos, cresce também o interesse pelo uso benéfico dos biossólidos ${ }^{2}$. Nos EUA, estima-se que 55\% do lodo produzido em 2004 era aplicado em atividades agrícolas, silvicultura e recuperação de áreas degradadas; na União Europeia, estima-se que em 2010 o uso agrícola respondesse por cerca de $50 \%$ das opções de destino final do lodo produzido; no Reino Unido, de acordo com estimativas de 2008, 67\% das 1,5 milhões de toneladas de lodo produzidas anualmente eram aplicadas na agricultura (LeBLANC et al., 2008).

Apesar dos vários benefícios associados ao uso agrícola de biossólidos, essa prática ainda é objeto de polêmicas, principalmente no que diz respeito aos impactos potencialmente adversos à saúde humana (CHROSTOWSKI e O'DETTE,
2002; JENKINS et al., 2007). Em vista disso, frequentemente, a resposta "oficial" é a imposição de normas rigorosas, incluindo critérios bastante exigentes de qualidade dos biossólidos e sérias restrições de uso. Por outro lado, não faltam críticas no sentido de que tais normas carecem da necessária e adequada abordagem de avaliação de risco (GALE, 2005; SIMMONDS, 2005; JENKINS et al., 2007; EISENBERG et al., 2008).

De acordo com Blumenthal et al. (2000), existem, basicamente, três abordagens para o estabelecimento de critérios de qualidade para a irrigação com águas residuárias, as quais podem ser extrapoladas para o uso agrícola de lodos de esgotos (SIMMONDS, 2005): (i) ausência de patógenos e, ou de organismos indicadores no lodo; (ii) a medida do risco atribuível à utilização agrícola do lodo dentre uma população exposta e (iii) a estimativa do risco mediante o emprego de modelos probabilísticos.

A primeira abordagem objetiva a ausência de perigos $^{3}$, tem sido referida como abordagem do "risco nulo" e criticada por rigor excessivo e fragilidade em termos de fundamentação epidemiológica (BLUMENTHAL et al., 2000). Na segunda abordagem, buscam - se evidências epidemiológicas de associação entre o fator de risco (uso agrícola de biossólidos) e a ocorrência de doença na população por meio de medidas de risco, visando à ausência de risco atribuível ${ }^{4}$. Entretanto, esse enfoque apresenta dificuldades práticas, por, dentre outros aspectos, depender de complexos estudos epidemiológicos (BLUMENTHAL et al., 2000).

Alternativamente, tomando como referência um nível de risco tido como "tolerável" e baseado na construção de "cenários de exposição", limites microbiológicos podem ser estabelecidos a partir de modelos de Avaliação Quantitativa de Risco Microbiológico (AQRM) (BLUMENTHAL et al., 2000, WHO, 2006a). Na realidade, a abordagem epidemiológica também poderia ser uti-

1 - As citações de massa de lodo de esgoto ou biossólido se referem à base seca.

2- O termo biossólidos tem sido empregado para designar o lodo de esgotos que foi suficientemente processado a fim de permitir, de forma segura, seu uso. O emprego desse termo objetiva destacar o potencial uso benéfico dos biossólidos ao invés de serem vistos apenas como resíduo a ser descartado (NRC, 2002; NEBRA, 2008).

3- O conceito de perigo é compreendido como as propriedades inerentes de um agente (biológico, químico ou físico) que, em uma dada condição de exposição, possam implicar algum efeito adverso à saúde, esse último traduzido no conceito de risco, o qual, em epidemiologia, refere-se à probabilidade de um evento ocorrer. A literatura especializada de reúso da água para irrigação tem empregado como sinônimo de perigo o termo risco potencial. 4- Em Epidemiologia, risco atribuível (risco em excesso ou diferença de risco) é definido como a proporção de um dano à saúde entre a população exposta que é devida a um fator de risco; o cálculo é feito por subtração entre dois coeficientes - de expostos e não expostos ao fator de risco - usualmente expressos pela taxa de incidência. A literatura especializada de reúso da água para irrigação tem empregado como sinônimo o termo risco real. 
lizada para estabelecer padrões tendo como referência o "risco tolerável", mas evidências epidemiológicas podem ser escassas e estudos epidemiológicos são, em geral, restritos ao estudo específico, além de apresentar, em alguns casos, baixa sensibilidade na detecção de riscos. Portanto, para determinadas situações, a AQRM pode se revelar como a única abordagem plausível, sendo especialmente adequada quando o risco tolerável se encontra abaixo do nível que pode ser mensurado por estudos epidemiológicos (BLUMENTHAL et al., 2000). Idealmente, evidências epidemiológicas e AQRM devem ser utilizadas como ferramentas complementares, como nas Diretrizes da Organização Mundial da Saúde (OMS) para o uso de águas residuárias na agricultura, em que o padrão bacteriológico $(E$. coli) para a abordagem de riscos bacterianos, virais e de protozoários foi definido a partir da AQRM (risco tolerável) e o padrão de helmintos foi estabelecido com base em evidências epidemiológicas (ausência de risco atribuível) (WHO, 2006a).

O objetivo desse trabalho foi avaliar critica e comparativamente as regulamentações sobre uso agrícola de biossólidos dos EUA, do Reino Unido e do Brasil. A regulamentação estadunidense foi selecionada pelo fato de ser uma das normas vigentes mais antigas e ser considerada referência no cenário mundial. No caso do Reino Unido, a escolha se deu pelo fato da mesma ser representativa dos países da União Europeia, uma vez que não somente ratifica, mas amplia e detalha o especificado pela Comissão Europeia. $\mathrm{O}$ artigo é desenvolvido procurando-se identificar os princípios teórico-metodológicos que fundamentam essas peças normativas, além de convergências e divergências entre as mesmas. Serão abordados nesse texto apenas os aspectos relativos à qualidade microbiológica dos biossólidos e os respectivos riscos à saúde humana.

Apresentação das regulamentações sobre uso agrícola de biossólidos dos Estados Unidos, do Reino Unido e do Brasil

\section{Estados Unidos- Norma 503}

Em 1993, a Agência de Proteção Ambiental dos
Estados Unidos (USEPA) promulgou os Standards for the Use or Disposal of Sewage Sludge, Code of Federal Regulations, Part 503 of the Clean Water Act, regulamentação esta usualmente denominada Part 503 Rule, ou aqui de "Norma 503” (USEPA, 1994). Segundo essa norma, as exigências e restrições para aplicação no solo dependem, em primeira instância, da qualidade do biossólido, definida em duas categorias - Classe A e Classe B.

Para a produção de biossólidos Classe B, o lodo deve ser tratado por Processos de Redução Significativa de Patógenos (PRSP), mas a qualidade microbiológica é estabelecida, essencialmente, em termos de coliformes termotolerantes (CTer): $<2 \times 10^{6}$ Cter / g de sólidos totais (ST) (Tabela 1). Dentre os PRSP, encontram-se: (i) digestão aeróbia, (ii) secagem ao ar; (iii) digestão anaeróbia; (iv) compostagem e (v) estabilização com cal. A esses processos são associadas condições operacionais, tais como tempo, temperatura e $\mathrm{pH}$, não detalhadas aqui (USEPA, 1994; USEPA, 2003). Na realidade, a garantia da qualidade dos biossólidos Classe B pode ser avaliada tanto pela verificação do padrão bacteriológico do produto final quanto pela avaliação do processo de tratamento. Isto é, se as condições operacionais especificadas são observadas não é necessário o monitoramento microbiológico.

Para produção de biossólidos Classe A, o lodo deve ser submetido a Processos de Redução Adicional de Patógenos (PRAP), alcançando um dos seguintes critérios: (i) < 1.000 Cter/g ST ou (ii) < 3 Salmonella spp./ 4 g ST (Tabela 1). Além disso, os requisitos de uma das seguintes alternativas devem ser atendidos: (iii) tempo $\mathrm{x}$ temperatura - uma dada temperatura (elevada) deve ser mantida por um período de tempo pré-determinado ou (iv) tratamento alcalino, em condições controladas de tempo, temperatura, $\mathrm{pH}$ e teor de sóli$\operatorname{dos}^{5}$ ou (v) o lodo é tratado por PRAP ou processo equivalente. Alternativamente às opções (iii) (iv) e (v), a qualidade Classe A pode ser verificada pelo monitoramento microbiológico de acordo com os seguintes critérios: (vi) $<1$ unidade formadora de placa (UFP) de vírus entéricos por 4 gramas de sólidos totais e (vii) $<1$ ovo viável de helmintos por 4 gramas de sólidos totais. Den-

5- Os critérios de tempo e temperatura e de estabilização alcalina para a produção de biossólidos Classe A podem ser verificados em documentos referentes à Norma 503 (USEPA, 1994; USEPA, 2003). 


\begin{tabular}{|c|c|c|c|c|}
\hline País & E. coli ou CTer & Salmonella & Vírus entéricos & Ovos de helmintos \\
\hline \multicolumn{5}{|c|}{ Biossólidos Classe A } \\
\hline EUA & $<10^{3} \mathrm{CTer} / \mathrm{g}$ ST & $<3$ NMP / 4 g ST & $<1$ UFP / 4 g ST & $<1 / 4 \mathrm{~g} \mathrm{ST}$ \\
\hline Reino Unido & $<10^{3}$ E. coli / g ST & ND em 2 g ST(1) & NE & NE \\
\hline Brasil & $<10^{3}$ CTer / g TS & ND em $10 \mathrm{~g}$ ST & $<0,25$ UFP ou UFF/g ST & $<0,25 / g$ ST \\
\hline \multicolumn{5}{|c|}{ Biossólidos Classe B } \\
\hline EUA & $<2 \times 10^{6}$ CTer / g ST & NE & NE & NE \\
\hline Reino Unido & $<10^{5}$ E. coli / g ST & NE & NE & NE \\
\hline Brasil & $<10^{6} \mathrm{CTer} / \mathrm{g} \mathrm{ST}$ & NE & NE & $<10 / \mathrm{g} \mathrm{ST}$ \\
\hline
\end{tabular}

CTer: coliformes termotolerantes; NMP: número mais provável; UFP: unidade formadora de placa; UFF: unidade formadora de foco; ST: sólidos totais; ND: não detectável; NE não especificado. (1) Environment Agency (2004)

Tabela 1 - Padrões de qualidade microbiológica de biossólidos nos EUA, Reino Unido e Brasil.

\begin{tabular}{|c|c|c|c|c|c|c|}
\hline \multirow{3}{*}{ País } & \multicolumn{4}{|c|}{ Intervalo para Cultivo (C) / Colheita (Co) ${ }^{(2)}$} & \multirow{3}{*}{$\begin{array}{l}\text { Pastejo (P), } \\
\text { cultivo (C) ou } \\
\text { colheita (Co) } \\
\text { de forrageiras } \\
\text { e pastagens }\end{array}$} & \multirow{3}{*}{$\begin{array}{l}\text { Acesso pú- } \\
\text { blico }\end{array}$} \\
\hline & \multicolumn{3}{|c|}{ Culturas alimentícias } & \multirow{2}{*}{$\begin{array}{l}\text { Culturas não } \\
\text { alimentícias }\end{array}$} & & \\
\hline & $\begin{array}{l}\text { Rente ao nível } \\
\text { do solo }\end{array}$ & Raízes & Outras & & & \\
\hline \multicolumn{7}{|c|}{ Biossólidos Classe A } \\
\hline EUA & SR & SR & SR & SR & SR & SR \\
\hline Reino Unido & 10 meses $(\mathrm{Co})$ & 10 meses (Co) & 10 meses (Co) & $\begin{array}{l}3 \text { semanas } \\
\text { (Co) }\end{array}$ & $\begin{array}{c}3 \text { semanas }(P) \\
(C o)\end{array}$ & \\
\hline Brasil & 48 meses $(C)$ & 48 meses $(C)$ & SR & SR & 24 meses $(C)$ & 30 dias \\
\hline \multicolumn{7}{|c|}{ Biossólidos Classe B } \\
\hline EUA & 14 meses $^{(3)}$ & $\begin{array}{l}\text { 20-38 meses } \\
(\mathrm{Co})^{(3)(4)}\end{array}$ & 30 dias $(\mathrm{Co})$ & 30 dias $(\mathrm{Co})$ & $30 \operatorname{dias}(P)$ & $\begin{array}{c}30 \text { dias-12 } \\
\text { meses }^{(5)}\end{array}$ \\
\hline Reino Unido & $\begin{array}{l}12-30 \text { meses } \\
(\mathrm{Co})^{(6)}\end{array}$ & $\begin{array}{l}\text { 12-30 meses } \\
(\mathrm{Co})^{(6)}\end{array}$ & $\begin{array}{l}\text { 12-30 meses } \\
(\mathrm{Co})^{(6)}\end{array}$ & $\begin{array}{l}3 \text { semanas } \\
\text { (Co) }\end{array}$ & $\begin{array}{l}3 \underset{\text { semanas }}{(\mathrm{Co})^{(7)}} \\
\end{array}$ & \\
\hline Brasil & NP & NP & NP & 6 meses $(C)^{(8)}$ & NP & 12 meses \\
\hline
\end{tabular}

SR: sem restrição; NP: não permitido; (1) Informações resumidas do conteúdo mais detalhado das normas; (2) Intervalo mínimo após a aplicação de biossólidos; (3) Incluindo hortaliças; (4) O intervalo de 20 meses é aplicado quando os biossólidos permanecem na superfície do solo por quatro meses ou mais antes de serem incorporados no solo; o intervalo de 38 meses é aplicado quando o biossólido permanece na superfície menos de quatro meses até a incorporação; (5) Os intervalos de 30 dias e 12 meses se aplicam a situações com, respectivamente, baixo e elevado potencial de exposição pública, no segundo caso incluindo a aplicação em parques e jardins; (6) Os intervalos de 12 e 30 meses aplicam-se, respectivamente, a hortaliças ingeridas cruas e a outras verduras e legumes; (7) aplicação superficial não é permitida em pastos; (8) somente cultivo de café, silvicultura, culturas para produção de fibras e óleos, com a aplicação mecanizada, em sulcos ou covas, seguida de incorporação; o intervalo de 6 meses se aplica no caso de colheita manual.

Tabela 2 - Restrições estabelecidas para uso agrícola de biossólidos nas regulamentações dos EUA, Reino Unido e Brasil (1) 
tre os PRAP, encontram-se: (i) compostagem; (ii) secagem térmica; (iii) tratamento térmico; (v) irradiação com raios beta e (vi) pasteurização. Aos PRAP são também associadas condições operacionais mínimas (USEPA, 1994; USEPA, 2003).

Caso os biossólidos Classe A atinjam também requisitos especificados para redução de metais e de vetores, podem ser utilizados sem quaisquer restrições, incluindo a possibilidade de comercialização ou distribuição e a aplicação em gramados e jardins residenciais. Essas últimas opções de uso não são permitidas para biossólidos Classe $B$, os quais, no entanto, podem ser aplicados em grande escala em solos agrícolas e florestais, em recuperação de áreas degradadas e em locais públicos, desde que os requisitos de controle de vetores e de poluentes químicos sejam observados, bem como as restrições resumidas na Tabela 2 .

\section{Reino Unido - Safe Sludge Matrix}

No Reino Unido, o controle da aplicação de lodo de esgotos em solos é estabelecido, em primeira instância, na Sludge (Use in Agriculture) Regulations de 1989 (HMSO, 1989), a qual constitui, essencialmente, aplicação da Diretiva do Conselho da União Europeia 86/278/CEE de 1986 (CEC, 1986). Essas regulamentações são complementadas pelo Código de Boas Práticas (Code of Practice) emitido pelo Department of the Environment (DoE, 1996), o qual apresenta exigências mais detalhadas para o monitoramento da qualidade do lodo e do solo, além de restrições para a aplicação dos biossólidos. Contudo, o foco principal dessas normas está nas substâncias químicas potencialmente tóxicas.

Além das normas legais, existem instrumentos de autocontrole consensuados entre as empresas de saneamento, o setor atacadista de comércio de alimentos e órgãos governamentais, consubstanciados na Safe Sludge Matrix (ADAS, 2001). A Safe Sludge Matrix compreende uma combinação de orientações sobre níveis de tratamento e condições de aplicação dos biossólidos a diferentes culturas, em termos de permissão de pastejo ou colheita após a aplicação de biossólidos (Tabela 2). É vedado o uso de lodo não tratado em solo agrícola para produção de alimentos, bem como a aplicação superficial em pastos de biossólidos tratados por "processos convencionais".

Com respeito às duas categorias estabelecidas de tratamento de lodo, o "tratamento convencional” deve assegurar remoção de E. coli de 2 log e concentração máxima de $10^{5}$ E. coli / g ST, enquanto o "tratamento avançado" deve assegurar $6 \log$ de redução de E. coli, concentração máxima de $10^{3}$ E. coli /g ST e ausência de Salmonella spp. (Tabela 1).

Os critérios operacionais para processos de tratamento do lodo visando à produção de biossólidos por tratamento convencional ou avançado não são especificados na Matrix, muito embora existam recomendações a esse respeito no Code of Practice. Cabe ao produtor de lodo identificar os parâmetros de controle de processos e monitorá-los, a fim de assegurar que a redução (unidades logarítmicas) e os requisitos de qualidade do produto sejam alcançados. Para tanto, a abordagem de Análise de Perigos e Pontos Críticos de Controle (APPCC) tem sido adotada pelas empresas de saneamento (WATER UK, 2004).

\section{Brasil - Resolução CONAMA No 375 / 2006}

A Resolução Conama No 375 de 29 de agosto de 2006 (BRASIL, 2006) também estabelece dois níveis de qualidade de biossólidos. Em termos gerais, os padrões de qualidade microbiológica de biossólidos na resolução brasileira são similares aos dos EUA e do Reino Unido (Tabela 1). Para produção de biossólidos Classe A e Classe B, a Resolução 375/2006 estabelece que o lodo tenha que ser submetido aos mesmos processos de tratamento citados na Norma 503, ou seja, respectivamente, PRAP e PRSP.

O biossólido Classe A deve satisfazer todos os requisitos apresentados na Tabela 1 , significando, portanto, que o monitoramento deve abranger todos os organismos especificados (indicadores e patógenos). Com relação aos vírus, é estabelecido que o monitoramento para vírus entéricos deva, preferencialmente, incluir adenovírus e enterovírus (Poliovirus, Echovirus, Coxsackievirus), mas que sob circunstâncias específicas (endêmicas ou epidêmicas), a pesquisa de outros vírus, como rotavírus e vírus da hepatite A, pode ser requerida. Biossólidos Classe A podem, a princípio, ser aplicados em qualquer cultura, desde que as restrições resumidas na Tabela 2 sejam observadas.

Biossólidos Classe B somente podem ser aplicados em cafezais, culturas fibrosas ou oleaginosas ou na silvicultura, desde que sejam incorporados ao solo mecanicamente e que sejam obedecidas as restrições de colheita e de acesso público resumidas na Tabela 2. Adicionalmente, a aplica- 
ção de biossólidos Classe B tinha previsão de ser banida cinco anos após a publicação da Resolução 375/2006, a não ser que "sejam propostos novos critérios ou limites baseados em estudos de avaliação de risco e dados epidemiológicos nacionais, que demonstrem a segurança do uso do lodo de esgoto Classe B" (BRASIL, 2006).

Avaliação comparativa entre as regulamentações dos Estados Unidos, Reino Unido e Brasil

Essas três peças regulatórias assumem a abordagem de dupla barreira de proteção à saúde (tratamento do lodo e restrições de uso de biossólidos), estabelecendo dois níveis de qualidade de biossólidos (os quais, para efeito de uniformização de terminologia, serão aqui referidos como Classe A e Classe B) (Tabela 1), para os quais são estabelecidas diferentes restrições de aplicação (Tabela 2).

Pressupõe-se que tanto a qualidade microbiológica do biossólido Classe A quanto a do Classe B alcancem o mesmo nível de redução de risco / proteção à saúde. No caso do biossólido Classe A, pelo tratamento do lodo em si, reduzindo os patógenos a níveis abaixo dos limites de detecção. No que diz respeito ao biossólido Classe B, a redução do risco, ou a proteção à saúde, seriam alcançadas pela combinação de processos de tratamento que reduziriam os patógenos a níveis ainda detectáveis, e de restrições de cultivo e de acesso (humano e animal). Impõem-se, assim, intervalos de tempo entre a aplicação do biossólido e o momento da exposição, durante os quais o decaimento natural proporcionaria redução complementar de patógenos até concentrações abaixo dos limites de detecção (portanto, a níveis de proteção equivalentes àqueles alcançados por biossólidos Classe A) (NRC, 2002; USEPA, 2003).

Os critérios de qualidade Classe $\mathrm{A}$, em termos de padrão de E. coli ou coliformes termotolerantes são, essencialmente, os mesmos nos três países $\left(10^{3}\right.$ E. coli ou Cter / g ST). Nos EUA o padrão de coliformes termotolerantes é assumido como indicador da ausência de Salmonella. Assim, como controle de qualidade, a norma dos EUA exige que as exigências estabelecidas em termos de coliformes termotolerantes "ou" de Salmonella sejam cumpridas. Biossólidos Classe A também devem estar livres de vírus entéricos e ovos (viáveis) de helmintos (abaixo dos limites de detecção); entretanto, na Norma 503 essa condição pode ser demonstrada pelo monitoramento desses patógenos ou de variáveis de controle operacional dos processos de tratamento. Infere-se, portanto, que o padrão de coliformes termotolerantes não é assumido como indicador confiável da ausência de vírus entéricos e de ovos de helmintos, mas que as variáveis operacionais se prestam, sim, ao papel de indicadores da eficiência do tratamento e substituem o controle por meio do monitoramento de patógenos.

No Reino Unido, para ser designado como biossólido Classe A, o produto final deve apresentar concentração máxima de 103 E. coli/g ST e ausência de Salmonella spp. Adicionalmente, o "tratamento avançado" deve assegurar remoção de E. coli de 99,9999\%. Em geral, esses critérios parecem inconsistentes, visto que, dadas as densidades de E. coli usualmente encontradas no lodo bruto, uma redução de $6 \log _{10}$ deve facilmente garantir níveis de E. coli muito menores que $10^{3}$ org /g e populações de Salmonella bem abaixo do limite de detecção. Não existem exigências explícitas de ausência de outros patógenos (como vírus e helmintos), para os quais o controle é supostamente alcançado pela eficiência de tratamento e indicado pela redução específica de E. coli e, ou por variáveis de controle operacional dos processos de tratamento.

A categoria brasileira Classe A claramente reproduz a dos EUA, porém apresenta alguns aspectos mais rigorosos. Na Norma 503, biossólidos Classe A devem apresentar menos de 1.000 Cter/g ST ou menos de 3 salmonelas / 4 g ST (limite de detecção), mas, assim como no Reino Unido, na Resolução CONAMA 375/2006 essa alternativa é traduzida como "e". Além disso, a ausência de vírus entéricos e de ovos de helmintos também deve ser demonstrada pelo monitoramento do produto final e, diferentemente da abordagem da Norma 503 e do Reino Unido, a eficiência de tratamento (verificada por meio de variáveis de controle operacional) não pode ser utilizada em substituição ao monitoramento dos patógenos. Em outras palavras, a abordagem brasileira parece ignorar o fato de que monitoramento de rotina para patógenos não é prática viável, além de desconsiderar o próprio conceito de organismos indicadores e a utilidade de variáveis de controle operacional (incorporados nos procedimentos de APPCC no Reino Unido).

Os parâmetros microbiológicos da Norma 503 para biossólidos Classe A têm como referência 
os limites de detecção dos métodos disponíveis à época (1993) para a pesquisa de patógenos, os quais, por definição (ou por razões logísticas), são baseados em um dado tamanho amostral (em termos de massa). Essas questões explicam os limites adotados, aparentemente estranhos, como $<3$ salmonelas (NMP) $/ 4$ g ST, $<1$ enterovírus (UFP) $/ 4 \mathrm{~g}$ ST e $<1$ ovo de helminto/4 g ST. Entretanto, a ausência de microrganismos numa pequena quantidade de material não assegura sua ausência em amostras maiores provenientes da mesma fonte. Assim, poderia ser especulado (somente especulado) que essa seria a razão do limite brasileiro para Salmonella ser especificado com base na ausência em $10 \mathrm{~g}$, talvez objetivando um padrão mais rigoroso ou mais seguro.

O padrão da Norma 503 para biossólidos Classe B foi desenvolvido com base na premissa de que os PRSP resultam em concentrações de coliformes termotolerantes menores que $2 \times 10^{6}$ org./g e que, considerando os valores tipicamente encontrados no lodo não tratado, isso corresponderia à redução de, aproximadamente, 2 log de CTer, 1 log de vírus entéricos e 1,5 log de Salmonella (USEPA, 2003; FARRELL, 2005). Como apontado anteriormente, na norma dos EUA, a qualidade de biossólidos Classe B pode ser avaliada tanto pela verificação do padrão bacteriológico especificado quanto pela avaliação da eficiência dos processos de tratamentos, implicando que os parâmetros de controle operacional são aceitos como substitutos dos organismos indicadores (CTer).

No Reino Unido, processos de "tratamento convencional" são entendidos como aqueles que asseguram 2 log de redução de E. coli (consequentemente, de patógenos) e concentração máxima permitida no biossólido de $10^{5} \mathrm{E}$. coli / g ST. Portanto, os critérios britânico e estadunidense soam coerentes entre si. De toda forma, nos dois casos não existe padrão explícito de patógenos e a redução esperada desses organismos é evidenciada pela redução correspondente (ou pela concentração máxima permitida) de $E$. coli ou coliformes termotolerantes (organismos indicadores) ou pelos parâmetros de controle operacional dos processos de tratamento.

A Resolução CONAMA 375/2006 estabelece um padrão de coliformes termotolerantes para biossólidos Classe B bem similar ao da Norma $503\left(<10^{6}\right.$ CTer/g ST) e um limite de ovos de hel- mintos bastante permissivo $(<10$ ovos viáveis/g ST), muito provavelmente sem qualquer fundamentação de avaliação de risco. Poder-se-ia inferir que o padrão de coliformes é entendido como indicador de alguma remoção (não especificada) de vírus entéricos e bactérias patogênicas por meio dos PRSP, mas, obviamente, não de ovos de helmintos. Entretanto, assim como para Classe A, a qualidade de biossólidos Classe B não pode ser assegurada com base na eficiência de tratamento. Mais uma vez, o conceito de parâmetros substitutos parece ter sido ignorado.

De acordo com a abordagem da dupla barreira de proteção, restrições de uso de biossólidos deveriam promover proteção adicional quando o tratamento por si só não é uma medida suficiente para remover "completamente" os organismos patogênicos. Essa é precisamente a lógica da Norma 503 para biossólidos Classe A, pois não existem restrições para o uso dessa categoria (Tabela 2), que é considerada "livre de patógenos”. Isso poderia ser visto como um clássico exemplo da tão chamada abordagem de "risco nulo" encontrada em algumas normas de reúso de águas residuárias, como nos Guidelines for Wastewater Use da USEPA (BLUMENTHAL et al., 2000; USEPA, 2004).

No entanto, no Reino Unido, mesmo que "tratamentos avançados" sejam entendidos como "processos capazes de eliminar patógenos", a regulamentação britânica impõe intervalos de colheita/pastejo quando biossólidos tipo Classe A são aplicados em pastagens e forrageiras (3 semanas) ou em culturas alimentícias (verduras e legumes) (10 meses), sendo esses ingeridos crus ou não (Tabela 2). A legislação brasileira estabelece restrições ainda mais rigorosas para o uso de biossólidos Classe A, impondo longos intervalos entre a aplicação do biossólido no solo e o cultivo de culturas comestíveis (novamente, sendo essas ingeridas cruas ou não) (48 meses) e pastagens (24 meses) (Tabela 2). Ressalta-se que as restrições da Resolução CONAMA 375/2006 são fixadas em referência ao plantio (cultivo), o que acrescenta intervalos de tempo ainda maiores até a colheita ou pastejo. Em suma, as exigências britânicas e brasileiras para biossólidos Classe A aparentam ser extremamente conservadoras, algo como uma abordagem de risco "menor que nulo"!

Como discutido anteriormente, as restrições para o uso de biossólidos Classe B são impostas 
com vistas à redução adicional de patógenos por processos de decaimento natural, objetivando, assim, o mesmo nível de proteção alcançado no caso de biossólidos Classe $\mathrm{A}$. As restrições à utilização de biossólidos Classe B estabelecidas na Norma 503 foram desenvolvidas levando em consideração a sobrevivência dos patógenos no solo, a qual pode variar em faixas tão amplas quanto dias e meses, dependendo do tipo de patógeno, da concentração inicial dos patógenos, da taxa e do método de aplicação do biossólido e das condições climáticas. Por esse motivo, a USEPA baseou suas restrições em "patógenos-referência" e em condições de exposição tidas como representativas e conservadoras o suficiente para permitir o uso dos biossólidos em qualquer região dos EUA e nos mais variados tipos de aplicação (NRC, 2002). A referência central foi a sobrevivência de ovos de helmintos, os quais são reconhecidos como os organismos mais resistentes (USEPA, 2003). É importante salientar que o padrão de coliformes termotolerantes para biossólidos Classe B é 2.000 vezes menos restritivo do que para biossólidos Classe A. Portanto, o cumprimento das restrições de uso e manejo é tido como fundamental e aí, provavelmente, reside a razão para o rigor de tais exigências em termos do tempo decorrido entre a aplicação dos biossólidos e da colheita das culturas ou do acesso de pessoas e animais.

Em relação às restrições para os diferentes usos de biossólidos Classe B, as condições climáticas brasileiras são, comparadas às dos EUA e do Reino Unido, em tese e em geral, menos favoráveis à sobrevivência de patógenos, mas, ainda assim, a Resolução Conama 375/2006 estabelece critérios muito mais restritivos, ao ponto de proibir a aplicação em culturas alimentícias e pastagens. Mais uma vez, a abordagem brasileira aparenta ser extremamente conservadora, exceto, contraditoriamente, pelo padrão bastante permissivo de ovos de helmintos.

Dado que as restrições fixadas para biossólidos Classe B foram desenvolvidas com base no que seria suficiente para reduzir os patógenos a concentrações abaixo do limite de detecção no momento de exposição ao público (NRC, 2002; USEPA, 2003), assim como no caso da Classe A, isso poderia também ser interpretado como abordagem de risco nulo. Entretanto, questionamentos têm sido levantados a respeito da real efetividade dessas restrições, uma vez que não existem exigências para que a redução de patógenos seja confirmada a partir de monitoramento de campo (NRC, 2002; FARRELL, 2005). Se por um lado isso poderia justificar a adoção de medidas conservadoras, por outro, poder-se-ia contra-argumentar que as restrições estabelecidas pela Norma 503 são injustificadamente restritivas (e mais ainda as da legislação brasileira).

Vantagens e limitações da abordagem de avaliação quantitativa de risco microbiológico

Considerando que, por razões logísticas, os limites de detecção de patógenos em biossólidos são baseados no tamanho da amostra em análise (usualmente pequena) e que esses limites podem mudar à medida que os métodos são aperfeiçoados, normas que têm como padrão o limite de detecção podem levar a falsa percepção de proteção (SIMMONDS, 2005). Além disso, sem a abordagem de avaliação de risco, tais normas podem ser excessivamente rigorosas impondo encargos desnecessários. Em resumo, a abordagem do "risco nulo" não somente é pouco confiável, mas também, talvez, desnecessária.

Embora possa haver referência implícita à avaliação de risco na norma dos EUA (justificada pela histórica falta de evidências sobre impactos na saúde humana), seus padrões microbiológicos são reconhecida e unicamente baseados no desempenho operacional dos processos de tratamentos (NRC, 2002). Também o é o marco regulatório do Reino Unido, embora esse apresente abordagem mais ampla ao incorporar procedimentos de APPCC (WATER UK, 2004). Quanto à Resolução CONAMA 375/2006, tendo como nítida referência a Norma 503, também carece de fundamentação em avaliação de risco. Em suma, nota-se, nas três regulamentações, a ausência do emprego adequado da abordagem de avaliação de risco, significando dizer que não há de fato caracterização dos riscos associados à utilização de biossólidos Classe A ou Classe B.

$\mathrm{O}$ enfoque de avaliação de risco permite o preenchimento de algumas lacunas não devidamente abordadas por essas três regulamentações, subsidiando eventuais atualizações e, até mesmo, preservando-as de críticas, por vezes justificadas, por vezes não. Por exemplo, a utilização de AQRM proporcionaria: (i) preencher lacunas de informação devidas à insuficiência (se não à ausência) de evidências epidemiológicas 
associadas à exposição ao uso de biossólidos; (ii) a comparação mais consistente entre os níveis de risco / proteção da saúde pública associados ao uso de biossólidos Classe A e Classe B; (iii) uma análise mais detalhada dos diversos cenários de exposição / modos de transmissão, incluindo o risco aos trabalhadores no momento da aplicação do biossólido, em geral negligenciado nas normas vigentes (JENKINS et al., 2007); (iv) em conjunto com os demais componentes da análise de risco (gestão de risco e comunicação de risco), estabelecer padrões de qualidade associados a determinado nível de risco tido como tolerável, bem como efetivamente aceito pelos vários setores interessados (por exemplo, os setores de saúde e saneamento, além do público em geral) (BEECHER et al., 2005).

Entretanto, uma abordagem consistente de AQRM depende da disponibilidade de dados e de informações confiáveis, incluindo: (i) a ocorrência de patógenos em biossólidos, sua dinâmica no ambiente e a contaminação esperada de diferentes culturas cultivadas com biossólidos; (ii) a qualidade real do biossólido produzido por "Processos de Redução Significativa de Patógenos" e "Processos de Redução Adicional de Patógenos"; (iii) o significado real dos padrões atuais que têm por base organismos indicadores, ou seja, a relação patógenos / organismos indicadores em biossólidos Classe A e Classe B, e a confiabilidade dos usuais organismos indicadores e (iv) a confiabilidade dos métodos analíticos atualmente disponíveis para a detecção e enumeração de patógenos em amostras ambientais e de biossólidos.

Nesse sentido, é importante reconhecer o fato de que os organismos-referência utilizados pela USEPA para a elaboração da Norma 503 (em 1993!) foram selecionados para representar os patógenos mais frequentemente encontrados em lodos de esgoto (ex: Salmonella e enterovírus foram utilizados como indicadores de um conjunto mais amplo de bactérias e vírus entéricos), até porque à época existiam métodos padronizados disponíveis para detecção e quantificação desses organismos. Entretanto, desde a publicação da Norma 503, os métodos analíticos têm sido aperfeiçoados e vários outros patógenos têm sido detectados em lodos de esgotos (SIDHU e TOZE, 2009). Sendo assim, as normas atuais não necessariamente asseguram o risco nulo esperado de um biossólido ou ambiente (solos e plantas) su- postamente livre de patógenos.

A literatura mais recente reconhece como limitação o fato de que as regulamentações dos EUA e do Reino Unido carecem de melhor fundamentação em avaliação de risco (GALE, 2005; SIMMONDS, 2005; JENKINS et al., 2007; EISENBERG et al., 2008). Aproximadamente 15 anos após a promulgação da Noma 503, e considerando sua influência sobre a regulamentação de biossólidos no Brasil, é chegada a hora de abordar a questão em bases mais consistentes. $\mathrm{O}$ avanço científico na área de AQRM tem permitido a estimativa de riscos associados a diferentes cenários de exposição, servindo de base para o desenvolvimento de diretrizes e padrões para água potável (USEPA, 2006; WHO, 2006b) e para utilização de águas residuárias (WHO, 2006a). Mais recentemente, a abordagem da AQRM tem sido estendida para o uso de biossólidos (GALE, 2005; EISENBERG et al., 2008; GERBA et al., 2008), expondo limitações das normas vigentes. Por exemplo, Gale (2005) estimou que o uso de biossólidos tratados por processos convencionais (digestão anaeróbia) no cultivo de cenouras, considerando o decaimento no solo por 1-3 meses, resultaria em riscos anuais de infecção por Salmonella, Giardia, Cryptosporidium e enterovírus em ordens de grandeza de $10^{5}-10^{9}$. Se considerados os tempos entre a aplicação de biossólidos e a colheita, especificados na Safe Sludge Matrix (Tabela 2), os respectivos riscos seriam praticamente inexistentes. Para efeito de comparação, os riscos anuais assumidos como aceitáveis na formulação de normas de qualidade da água potável pela OMS e pela USEPA são da ordem de $10^{-4}$ (USEPA, 2006, WHO, 2006b). BASTOS et al. (2009), aplicando AQRM em cenários hipotéticos de exposição adaptados a realidade brasileira, sugerem que a Resolução CONAMA 375/2006 possa ser demasiadamente rigorosa para o padrão Classe A, tanto nos critérios de qualidade do lodo, quanto, principalmente, nas restrições de uso. Os autores sugerem ainda que o mero banimento do uso de lodo Classe B possa ser medida desnecessariamente rigorosa e que seu uso parece defensável, desde que acompanhado de medidas adequadas de proteção à saúde, com especial atenção à saúde ocupacional.

\section{Conclusões}

As reflexões levantadas nesse trabalho delineiam desafios à academia, às empresas de sa- 
neamento e aos órgãos reguladores no que diz respeito à adequada apropriação e aplicação da metodologia de AQRM para a crítica bem fundamentada da Resolução CONAMA 375/2006, com vistas ao processo continuado de sua revisão e atualização. Para isso, torna-se necessária a obtenção de dados e informações (provenientes de pesquisa locais e, ou da experiência internacional) que permitam a construção de cenários de exposição específicos e realísticos. Será ainda preciso problematizar outra questão central na aplicação de AQRM: o que constitui risco tolerável no contexto brasileiro?

\section{Agradecimentos}

Ao CNPq pela concessão de bolsas aos dois primeiros autores para a realização do pós-doutorado na Universidade de Leeds-UK, instituição do terceiro autor e à qual são também registrados os devidos créditos.

\section{Referências}

ADAS. AGRICULTURAL DEVELOPMENT AND ADVISORY SERVICE. The sewage sludge matrix. Guidelines for the application of sewage sludge to agricultural land. Wolverhampton, 2001. Disponível em:< http://www.adas. co.uk/LinkClick.aspx?fileticket=f_CX7x_

$\mathrm{v} 4 \mathrm{nY} \% 3 \mathrm{D} \&$ tabid $=211 \& \mathrm{mid}=664>$. Acesso em: 21 out 2009.

BASTOS, R.K.X.; BEVILACQUA, P.D; DIAS, G.M.F.; BARONY, F.J.A. Análise crítica da legislação brasileira para uso agrícola de lodos de esgotos na perspectiva da avaliação quantitativa de risco microbiológico. Revista AIDIS de Ingeniería y Ciencias Ambientales: Investigación, Desarrollo y Práctica, v.2, n.1, p.143-59, 2009.

BEECHER, N.; HARRISON, E.; GOLDSTEIN, N.; McDANIEL, M.; FIELD, P.; SUSSKIND, L. Risk perception, risk communication, and stakeholder involvement for biosolids management and research. Journal of Environmental Quality. v.34, p.122-128, 2005.

BLUMENTHAL, U.J.; MARA, D.D., PEASEY, A.; RUIZ-PALACIOS, G.; STOTT, R. Guidelines for the microbiological quality of treated wastewater used in agriculture: recommendations for revising WHO guidelines. Bulletin of the World Health Organization, v.78, n.9, p.1104-16, 2000.

BRASIL. Conselho Nacional do Meio Ambiente.
Resolução no 375 de 29 de agosto de 2006. Define critérios e procedimentos, para o uso agrícola de lodos de esgoto gerados em estações de tratamento de esgoto sanitário e seus produtos derivados, e dá outras providências Brasília, DF: Diário Oficial da União, 30 de ago. 2006.

CEC. COUNCIL OF THE EUROPEAN COMMUNITIES. Council Directive 86/278/EEC of 12 June 1986 on the protection of the environment, and in particular of the soil, when sewage sludge is used in agriculture. Official Journal L, v.181, p.6-12, 1986.

CHROSTOWSKI, P.C.; O’DETTE, R.G. Demystifying the great biosolids debate. Sound science removes emotion from decisions about biosolids recycling. Pollution Engineering, v.34, n.8, p. 23-7, 2002.

DoE. DEPARTMENT OF THE ENVIRONMENT. Code of practice for agricultural use of sewage sludge. Ruislip, 1996. 20 p.

EISENBERG, J.N.S.; MOORE, K.; SOLLER, J.A.; EISENBERG, D.; COLFORD, J.M. Microbial risk assessment framework for exposure to amended sludge projects. Environmental Health Perspectives, v.116, n.6, p.727-33, 2008.

ENVIRONMENT AGENCY. The Microbiology of Sewage Sludge (2004) - Part 4 - Methods for the detection, isolation and enumeration of Salmonellae. Methods for the examination of waters and associated materials. Bristol, UK: Environment Agency, 2004.

FARRELL, J.B. Pathogen reduction requirements of 40 CFR Part 503: their origin, evaluation, new reduction approaches. In: SMITH, J.E.; MILLNER, P.D.; JAKUBOWSKI, W.; GOLDSTEIN, N.; RYNK, R. Contemporary perspectives on infectious disease agents in sewage sludge and manure. Emmaus: The JG Press Inc, 2005. p.217-29.

GALE. P. Land application of treated sewage sludge: quantifying pathogen risks from consumption of crops. Journal of Applied Microbiology, v.98, n.2, p.380-96, 2005.

GERBA, C.P.; CAMPO, N.C.; BROOKS, J.P.; PEPPER, I.L. Exposure and risk assessment of Salmonella in recycled residuals. Water Science and Technology. v.57, n.7, p.1061-65, 2008.

HMSO. HER MAJESTY STATIONARY OFFICE. Statutory Instrument No. 1263. The Sludge (Use in 
Agriculture) Regulation. London, 1989. Disponível em: <http://www.opsi.gov.uk/si/si1989/ Uksi_19891263_en_1.htm>. Acesso em: 21 out 2009 .

IRANPOUR, R.; COX, H. H. J.; KEARNEY, R. J.; CLARK, J. H.; PINCINCE, A. B.; DAIGGER, G. T. Regulations for biosolids land application in U.S. and European Union. Journal of Residuals Science \& Technology, v.1, n.4, p.209-22, 2004.

JENKINS, S.R.; ARMSTRONG, C.W.; MONTI, M.M. Health effects of biosolids applied to land: Available scientific evidence. Virginia, 2007. 34 p. Disponível em: <www.vdh.state.va.us/epidemiology/ DEE/documents/Biosolidsfinal.pdf>. Acesso em: 02 nov 2009.

LeBLANC, R.J.; MATTHEWS, P.; RICHARD, R.P. (ed.). Global atlas of excreta, wastewater sludge, and biosolids management: moving forward the sustainable and welcome uses of a global resource welcome uses of a global resource. Nairobi, 2008. 608 p. Disponível em: <http://esa.un.org/iys/ docs/san_lib_docs/habitat2008.pdf>. Acesso em: 19 out 2009 .

MACHADO, M.F.S.; FIGUEIREDO, R.F.; CORAUCCI FILHO, B. Produção brasileira de lodos de esgotos. Sanare - Revista Técnica da Sanepar, v.22, n.22, p.66-74, 2004.

NEBRA. NORTH EAST BIOSOLIDS AND RESIDUALS ASSOCIATION. Information update: official usage of the term "biosolids". Tamworth, 2008. 7 p. Disponível em <http://www.nebiosolids.org/ uploads/pdf/Biosolids-theWord-NEBRA08.pdf>.

Acesso em: 2 nov 2009

NRC. NATIONAL RESEARCH COUNCIL. Biosolids applied to land: advancing standards and practices. Washington, 2002. 282 p.

SIDHU, J.P.S.; TOZE, S.G. Human pathogens and their indicators in biosolids: A literature review. Environment International, v.35, n.1, p.187-201, 2009

SIMMONDS, C. Pathogens in biosolids: risks and regulations. In: SMITH, J.E.; MILLNER, P.D.; JAKUBOWSKI, W.; GOLDSTEIN, N.; RYNK, R. Contemporary perspectives on infectious disease agents in sewage sludge and manure. Emmaus: The JG Press Inc, 2005. p 231-8.
USEPA. UNITED STATES ENVIRONMENTAL PROTECTION AGENCY. A plain English guide to the EPA 503 part biosolids rule. Washington, 1994 Disponível em: <http://www.epa.gov/OW-OWM. $\mathrm{html} / \mathrm{mtb} /$ biosolids/503pe/index.htm>. Acesso em: 21 out 2009 .

USEPA. UNITED STATES ENVIRONMENTAL PROTECTION AGENCY. Control of pathogens and vector attraction in sewage sludge. Cincinnati: 2003. 186 p. Disponível em: <http://www.epa.gov/nrmrl/pubs/625r92013/625r92013.htm>. Acesso em: 21 out 2009 .

USEPA. UNITED STATES ENVIRONMENTAL PROTECTION AGENCY. Guidelines for water reuse. Washington, 2004. 28 p.

USEPA. UNITED STATES ENVIRONMENTAL PROTECTION AGENCY. National primary drinking water regulations: Long term 2 enhanced surface water treatment rule. Washington, 2006. 653786p. (Final Rule. Federal Register, Part II, 40CFR, Parts 9, 141 and 142).

WATER UK. The application of HACCP procedures in the water industry: Biosolids treatment and use on agricultural land. London, 2004. 52 p.

WHO. WORLD HEALTH ORGANIZATION. Guidelines for the safe use of wastewater, excreta and greywater. Volume 2: Wastewater use in agriculture. Geneva: WHO, 2006a. 213 p.

WHO. WORLD HEALTH ORGANIZATION. Guidelines for drinking water quality [electronic resource]: Incorporating first addendum. Vol. 1, Recommendations. 3.ed. Geneva: WHO, 2006b. 595p. 


\section{E você achando que $100 \%$ fosse o máximo que alguém pudesse se dedicar.}

Sabesp 300\%: $100 \%$ de água tratada, $100 \%$ de esgoto coletado e $100 \%$ de esgoto tratado.

0 saneamento transforma a vida das pessoas. Por isso, não medimos esforços para levar, até 2014, 0 Sabesp 300\% para todos os municípios do interior atendidos pela Sabesp. E, até 2018, para todas as outras cidades atendidas por nós. Saiba mais acessando www.sabesp.com.br.

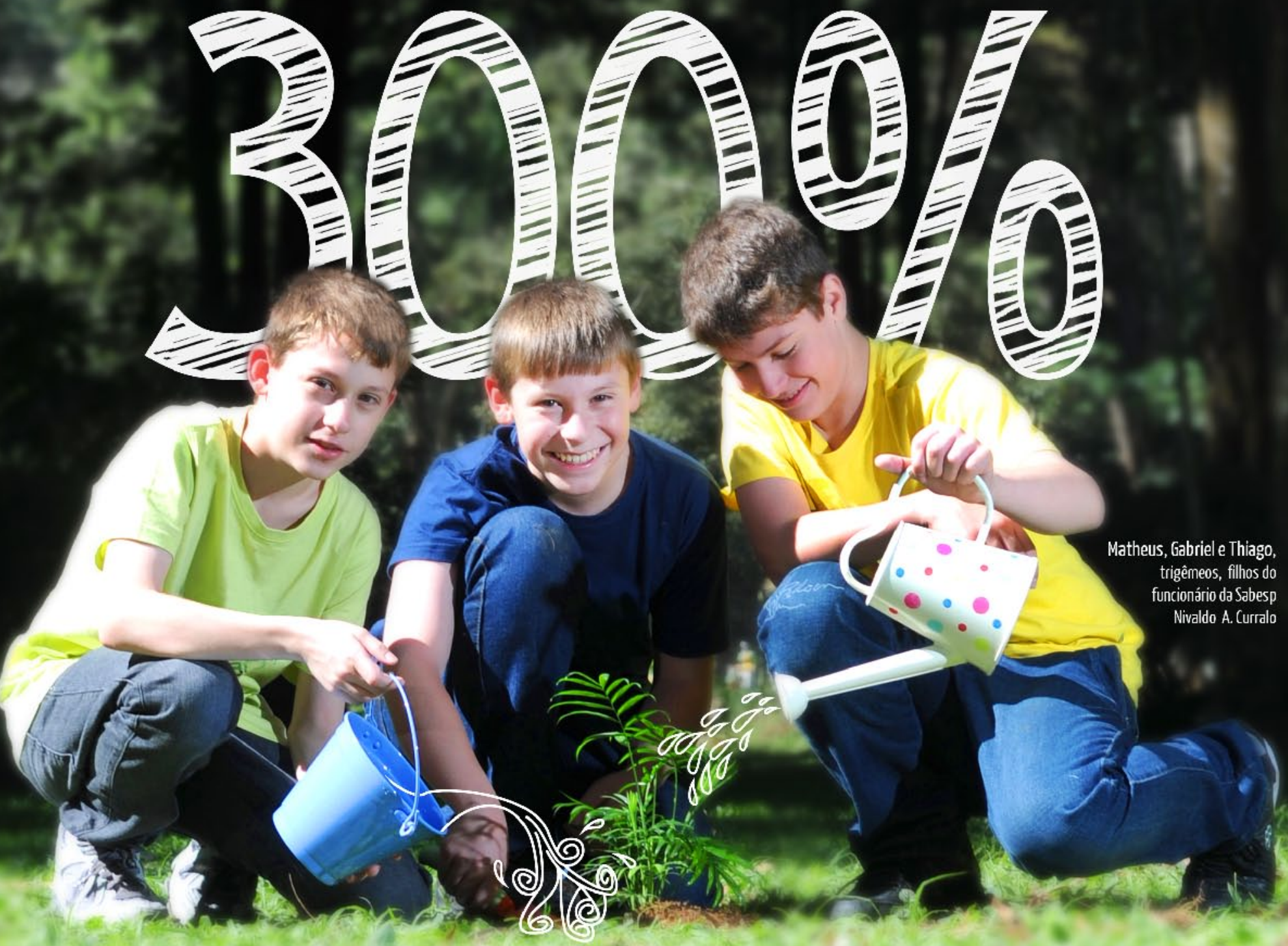

Sabesp.

Transformando vidas. 